\title{
The Research on the Effect Of Three kinds Of Growth Promoters on the Growth of Banana Transplanting Seedlings and The Resistant Physiology
}

\author{
Li Na Huang ${ }^{1, a}$, Zhenrong Yang ${ }^{2, b}$, Shimin Cheng ${ }^{3, c}$, \\ Zengxian Zhao ${ }^{4, d}$, Zisi Xie ${ }^{5,}$ and Shouxing Wei ${ }^{6, f^{*}}$ \\ ${ }^{1}$ Tropical Crops Genetic Resources Institute, Chinese Academy of Tropical Agricultural Sciences \\ (CARTA)/ National Cultivar Improvement Center of Tropical Fruit Tree /Hainan Tropical Fruit \\ Engineering Technology Research Center, Danzhou, 571737, China \\ a huanglinahappy@sina.com, ${ }^{\mathrm{b}} 540953238 @$ @q.com, ${ }^{\mathrm{c}} 867944012 @ q q . c o m,{ }^{\mathrm{d}}$ ghostmind@qq.com, \\ e64043545@qq.com, fshouxingwei@163.com
}

*The Corresponding Author

Keywords: Growth promoters; Banana transplanting seedlings; Growth; Resistant physiology

\begin{abstract}
Conventional sizes of banana false seeding as material, using pot experiment, the three growth promoters of the growth of the transplanting seedlings, nutrient uptake and resistant physiological effects. Results show that compared with the control, spraying the growth promoters of this experiment can improve the height of pseudo-stem of banana transplanting seedlings and proline content in the body, reduce the MDA content in leaf, an average of $13.65 \%$ and $13.92 \%$ respectively. Fresh spraying on the leaf amine ester $20 \mathrm{mg} / \mathrm{L}$ can also increase the new foliage area and the three foliage area, promote dry matter accumulation, increase the SOD activity. Shi alpha naphthyl acetic acid sodium $10 \mathrm{mg} / \mathrm{L}$ is the most beneficial to promote the banana transplanting seedlings NPK nutrients absorption, increased by $17.14 \%, 12.67 \%$ and $31.55 \%$, respectively; The activity of SOD and POD. Thus, banana transplanting seedlings cultivating process, fresh spraying on the leaf amine ester $20 \mathrm{mg} / \mathrm{L}$ can significantly promote the morphosis, increasing resistance of high false seeding; Spraying alpha naphthyl acetic acid sodium $10 \mathrm{mg} / \mathrm{L}$ promote k nutrient uptake. So in order to obtain robust banana transplanting seedlings, should consider to mix fresh spraying amine ester or interval $20 \mathrm{mg} / \mathrm{L}$, alpha naphthyl acetic acid sodium $10 \mathrm{mg} / \mathrm{L}$.
\end{abstract}

\section{Introduction}

The current domestic new planting banana more high quality without virus, false seeding of healthy growth. Thus to foster healthy, high quality, strong resistance of banana false seeding is the basis of the banana and stable yield, high yield [1-2]. However, most existing banana false seeding transplanting in summer and fall season, slow low survival rate of seedling length, grew weak, and even affect the growth of banana late tidy [3-4]; In addition, engraftment conventional secondary false seeding, banana field growth period is longer than the unable to avoid the cold in the winter and spring were hurt, easy cause crop failures, increase the risk of planting (4-6). At present, on the basis of cultivating strong banana secondary false seeding breeding older false seeding, the results show that the banana transplanting seedlings root system developed, without slow seedlings after transplanting field, shorten the banana field growth period, can decrease the incidence of a disease, can avoid cold, in the field in the winter and spring were extended for seedling, meet the needs of different growing period (5-9). Therefore, cultivating and transplanting provisonal planting banana went to will become a new orientation in the transformation of traditional banana planting patterns, the study of robust provisonal planting banana went to foster technology is of great significance for the banana production.

Plant growth regulator import farming, which is beneficial to the traditional cultivation system, the activation and crop resistance potential into full play [10]. Plant growth regulator nutrition divided into two categories: growth promoters and inhibitors. Accelerator is mainly promote cell growth, cell elongation, in particular, to speed up the plant stem and leaf growth, promote the 
germination, crops have a significant effect to increase production. The amine ester, compound sodium phenolate and alpha naphthyl acetic acid sodium nitrate and other growth promoters widely participate in the regulation of plant growth and development (8-15). Fresh research has shown that amine ester can promote crop biomass increase, promote crop growth and development, improve the activity of protective enzyme, enhance crop resistance, improve crop quality [11-13]. After phenol sodium nitrate can promote rape seedling, looks like the tomato, increase its resistance (4,8,13-15). Alpha naphthyl acetic acid sodium can promote cell division and enlargement, crop crop early mature, improve crop quality, effectively improve resilience of crops,13,16 [11]. Plant growth regulator because of its significant, rapid and efficient adjustment, popularization and application in practical production. Therefore, this experiment selected three kinds of common growth promoters, using different concentrations in banana transplanting seedlings cultivate the spraying process, the determination of different processing false seeding growth index, nutrient absorption and resistance index, comprehensive evaluation of different growth promoters in banana transplanting seedlings cultivate application effect of the kinds and concentrations in order to select the appropriate regulator, banana transplanting seedlings provide theoretical basis for cultivating technology.

Test Materials. selected crops: varieties of Brazil banana false seeding (six leaf), Chinese academy of tropical agriculture seedlings earth center provides; Selected the basin: black nutrition cup (specification (straight stem (high) : $16 \mathrm{~cm} \times 14 \mathrm{~cm}$ ).

Selected matrix: coconut chaff, physical and chemical properties of bulk density: $18.69 \mathrm{~g} / \mathrm{cm} 3$, total porosity: $79.65 \%$, PH: 5.81 , organic matter: $64.38 \%$, alkali solution nitrogen: $357.42 \mathrm{mg} / \mathrm{kg}$, available p: $821.66 \mathrm{mg} / \mathrm{kg}$, rapidly-available potassium: $28976.53 \mathrm{mg} / \mathrm{kg}$.

selected fertilizer urea $(46 \% \mathrm{~N})$ and potassium chloride $(\mathrm{K} 2 \mathrm{O})$ is $60 \%$, compound fertilizer (15-15-15).

Fresh growth promoters: amine ester (DA - 6) purity (98\%), compound phenol sodium nitrate (CSN) purity (98\%), alpha naphthyl acetic acid sodium (purity 98\%).

Test Method. Experiment using single-factor completely random design, fresh set amine ester $10 \mathrm{mg} / \mathrm{L}$, fresh amine ester $20 \mathrm{mg} / \mathrm{L}$, after phenol sodium nitrate $10 \mathrm{mg} / \mathrm{L}$, after $20 \mathrm{mg} / \mathrm{L}$ sodium nitrate of phenol, alpha naphthyl acetic acid sodium $10 \mathrm{mg} / \mathrm{L}$, alpha naphthyl acetic acid sodium 20 $\mathrm{mg} / \mathrm{L}$, a total of six processing, with no growth promoters as controls. Growth promoters in accordance with the uniform spraying on the leaf spraying concentration and back, a water drop. When spraying, separated with plastic film and other processing, to prevent cross contamination. Not the processing of spraying growth promoters, spray the same amount of water at the same time. On July 9, 2015, transplanting, slow seedlings every 12 days after treatment, a total of 5 times. $8 \mathrm{~d}$ after treatment to determine growth indexes, 15 seedlings, banana false seeding were observed every $10 \mathrm{~d}$ measurement. banana transplanting seedlings went to sizes of standard (see banana seedling somaclone quality standard (DB441900 06-2006 / T), after sampling on September 25. False seeding sampling points of aboveground and underground part; randomly selected healthy and growing in the 9 strains of banana transplanting seedlings sampling, then select fully expanded, more second foliage meat wrapped with aluminum foil after liquid nitrogen frozen under the condition of $80{ }^{\circ} \mathrm{C}$ cryogenic preservation, used for the determination of physiological index. Ensure the water content in $60 \% \sim 60 \%$ during test. The banana provisonal planting went banana seedlings per hill in the process of cultivating applied urea of compound fertilizer, potassium chloride $1.61 \mathrm{~g}$ and $4.27 \mathrm{~g} 7.49 \mathrm{~g}$, is divided into seven times in the way of sewage sludge.

Measurement Indicators and Methods. Leaf length, leaf width: unity with straightedge measuring trifoliate biggest long and wide. Leaf area $=$ leaf length $\mathrm{x}$ width $\mathrm{x} 0.76299+0.0266[4$, 8]; High false stem: unified with straightedge measuring from the substrate surface to the top banana two fully expanded leaf with the distance between the intersection of; False stem diameter: unified use vernier caliper from the substrate surface $2 \mathrm{~cm}$ in reading [8. After crushing of the sample after use - $\mathrm{H} 2 \mathrm{SO} 4$ - H2O2 elimination boiled with indophenol blue colorimetry test $\mathrm{N}$, molybdenum antimony colorimetry test $\mathrm{P}$, flame spectrophotometry to measure $\mathrm{K}$ [17].

Proline and malondialdehyde (MDA) content by using sulfosalicylic acid and glucosinolates 
barbituric acid determination method; Peroxidase (POD) and superoxide dismutase (SOD) activity, respectively by using guaiacol and nitroblue tetrazolium method (17-18). Above physiological indexes to sample Fresh Weight (Fresh Weight, FW) as a base for said.

Data Calculation and Processing. Test data are using Excel 2007 and SPSS 13.0 software for data processing and statistical analysis.

\section{The Results and Analysis}

The Banana Transplanting Seedlings the Influence of Growth. As shown in table 1, compared to the use of growth promoters can significantly improve the banana transplanting seedlings false stem height, average increased by 13.65\%; With fresh spraying amine ester $20 \mathrm{mg} / \mathrm{L}$ processing, compound sodium nitrate phenol false stem top $20 \mathrm{mg} / \mathrm{L}$, increased by $16.94 \%$ and $23.29 \%$ respectively. Fresh spraying amine ester $20 \mathrm{mg} / \mathrm{L}$ significantly increased leaf area and the new three piece of foliage area, increased by $25.09 \%$ and $25.09 \%$ respectively; Compound sodium nitrate phenol treatment can significantly increase the inverted three leaf area. Comprehensive the above results, a banana transplanting seedlings cultivate, fresh spraying amine ester $20 \mathrm{mg} / \mathrm{L}$ can significantly contribute to the growth of banana shape.

Table 1 the Influence of Growth Promoters on the Growth of the Banana Transplanting Seedlings

\begin{tabular}{|c|c|c|c|c|}
\hline Dealing with & $\begin{array}{l}\text { height of } \\
\text { pseudo-ste } \\
\text { m (cm) }\end{array}$ & $\begin{array}{l}\text { Thick of } \\
\text { pseudo-ste } \\
\mathrm{m}(\mathrm{mm})\end{array}$ & $\begin{array}{l}\text { The area of } \\
\text { new leaf }\left(\mathrm{cm}^{2}\right)\end{array}$ & $\begin{array}{l}\text { The area of the } \\
\text { reverse three leaf } \\
\left(\mathrm{cm}^{2}\right)\end{array}$ \\
\hline contrast & $\begin{array}{l}23.96 \pm 0.25 \\
d\end{array}$ & $\begin{array}{l}21.61 \pm 0.55 \\
\mathrm{a}\end{array}$ & $1742 \pm 116 b$ & $228.25 \pm 10.53 \mathrm{c}$ \\
\hline DA-610mg/L & $\begin{array}{l}25.92 \pm 0.36 \\
\text { c }\end{array}$ & $\begin{array}{l}23.12 \pm 0.37 \\
\mathrm{a}\end{array}$ & $2087 \pm 121 \mathrm{ab}$ & $259.81 \pm 11.13 \mathrm{bc}$ \\
\hline DA-620mg/L & $\begin{array}{l}28.02 \pm 0.88 \\
\mathrm{ab}\end{array}$ & $\begin{array}{l}23.49 \pm 0.16 \\
\mathrm{a}\end{array}$ & $2179 \pm 162 \mathrm{a}$ & $306.29 \pm 6.56 \mathrm{a}$ \\
\hline CSN 10mg/L & $\begin{array}{l}26.60 \pm 0.68 \\
\text { bc }\end{array}$ & $\begin{array}{l}22.60 \pm 0.75 \\
\mathrm{a}\end{array}$ & $2034 \pm 102 \mathrm{ab}$ & $265.11 \pm 11.32 \mathrm{~b}$ \\
\hline $\mathrm{CSN} 20 \mathrm{mg} / \mathrm{L}$ & $\begin{array}{l}29.54 \pm 0.63 \\
\text { a }\end{array}$ & $\begin{array}{l}23.06 \pm 0.98 \\
\mathrm{a}\end{array}$ & $2092 \pm 70 \mathrm{ab}$ & $274.63 \pm 12.65 \mathrm{~b}$ \\
\hline$\alpha-\mathrm{NSS} 10 \mathrm{mg} / \mathrm{L}$ & $\begin{array}{l}27.44 \pm 0.64 \\
\text { bc }\end{array}$ & $\begin{array}{l}21.81 \pm 0.44 \\
\mathrm{a}\end{array}$ & $1754 \pm 57 \mathrm{~b}$ & $231.19 \pm 9.53 \mathrm{c}$ \\
\hline$\alpha-\mathrm{NSS} 20 \mathrm{mg} / \mathrm{L}$ & $\begin{array}{l}25.86 \pm 0.33 \\
\mathrm{c}\end{array}$ & $\begin{array}{l}22.13 \pm 0.64 \\
\mathrm{a}\end{array}$ & $1754 \pm 93 \mathrm{~b}$ & $231.36 \pm 11.53 \mathrm{c}$ \\
\hline
\end{tabular}

Note: the value in the table represent the average $+/$ - standard error, the column between the different small letters mean significant differences between treatment ( $\mathrm{P}$ 0.05) or less, multiple comparison with Duncan new complex process, the same below.

The Effect on the Banana Transplanting Seedlings Growth and the Dry Matter Accumulation and Nutrient Absorption. The table 2 shows that compared to fresh spraying amine ester treatment can significantly improve the banana transplanting seedlings dry matter accumulation amount, average increased by $17.14 \%$; After phenol sodium nitrate $10 \mathrm{mg} / \mathrm{L}$ treatment can significantly increase the quality of dry matter, increased by $24.22 \%$. Fresh spraying amine ester $10 \mathrm{mg} / \mathrm{L}$, alpha naphthyl acetic acid sodium $10 \mathrm{mg} / \mathrm{L}$ treatment can significantly increase the banana provisonal planting than control went to nitrogen nutrient uptake, increased by $17.33 \%$ and $17.14 \%$, respectively; Especially alpha naphthyl acetic acid sodium $10 \mathrm{mg} / \mathrm{L}$ treatment can obviously improve the provisonal planting went to phosphorus potassium uptake, increased by $12.67 \%$ and $12.67 \%$ respectively. So, a banana transplanting seedlings cultivating process, the spraying of alpha naphthyl acetic acid sodium $10 \mathrm{mg} / \mathrm{L}$ most conducive to promoting the banana transplanting seedlings dry matter accumulation and $\mathrm{k}$ nutrient absorption. 
Table 2 Different Processing Banana Transplanting Seedlings Dry Matter Accumulation and

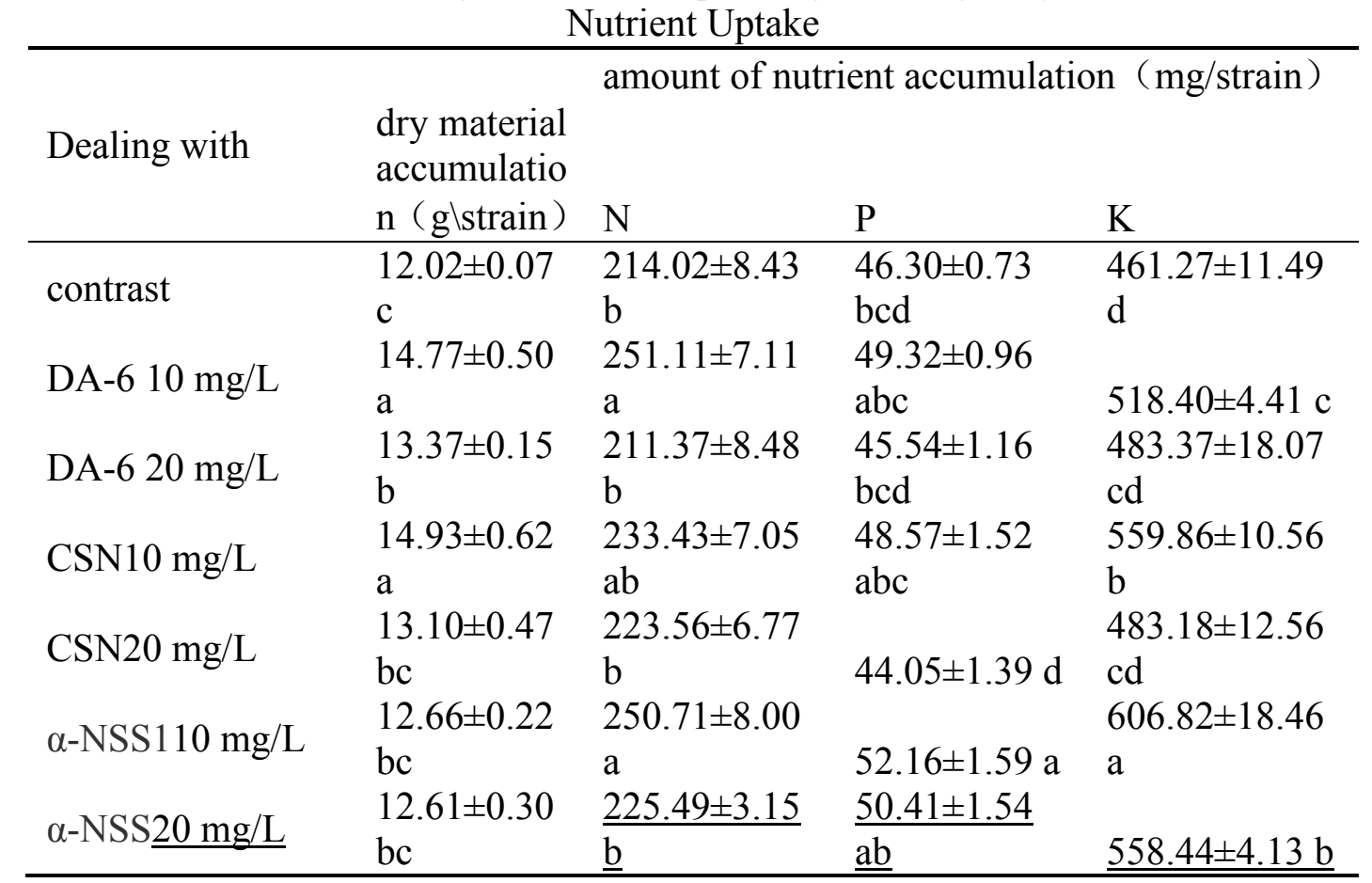

The Effect of the Banana Transplanting Seedlings on the Resistance Index. MDA is the final breakdown products of plant membrane lipid peroxidation, its content is higher, the more serious the damage to cell membrane [18]. The table 3 shows that growth promoters treatment can significantly reduce the MDA content than control, increase the content of proline, an average of $13.92 \%$ and increased by $22.56 \%$; With alpha naphthyl acetic acid sodium $20 \mathrm{mg} / \mathrm{L}$ deal with lowest MDA content, and to alpha naphthyl acetic acid sodium $10 \mathrm{mg} / \mathrm{L}$ deal with the highest content of proline. SOD and POD is one of the important members of the plant membrane protective enzyme system, the higher the active, the more protective of biofilm, the stronger the ability to withstand adversity and plants. Compared to fresh besides the amine ester $10 \mathrm{mg} / \mathrm{L}$ processing, the rest of the processing can improve the protective enzyme activity of leaf. After phenol sodium nitrate $20 \mathrm{mg} / \mathrm{L}$, alpha naphthyl acetic acid sodium $10 \mathrm{mg} / \mathrm{L}$ processing can significantly improve the provisonal planting went to SOD and POD in leaf, increased by $13.25 \%$ and $34.23 \%, 13.25 \%$ and $34.23 \%$ respectively; Fresh amine ester $20 \mathrm{mg} / \mathrm{L}$, alpha naphthyl acetic acid sodium $20 \mathrm{mg} / \mathrm{L}$ treatment can improve the SOD content in the leaves, after phenol sodium nitrate $10 \mathrm{mg} / \mathrm{L}$ can only improve the content of POD. Thus, a banana transplanting seedlings foster the application of amine ester, after phenol sodium nitrate, sodium alpha rootone three growth regulator can effectively reduce the leaf MDA content, proline content increased; Fresh amine ester only $20 \mathrm{mg} / \mathrm{L}$ to improve enzyme activity, with alpha naphthyl acetic acid sodium $10 \mathrm{mg} / \mathrm{L}$ processing effect is best.

Table 3 The Influence of Growth Promoters of the Resistance of Banana Transplanting Seedlings

\begin{tabular}{lllll}
\hline Dealing with & $\begin{array}{l}\text { MDA } \\
\text { content } \\
(\mu \mathrm{mol} / \mathrm{g})\end{array}$ & $\begin{array}{l}\text { proline } \\
\text { concentration } \\
(\mu \mathrm{g} / \mathrm{g})\end{array}$ & $\begin{array}{l}\text { SOD activity } \\
(\mathrm{U} /(\mathrm{g} \bullet \mathrm{FW}))\end{array}$ & $\begin{array}{l}\text { POD activity } \\
(\mathrm{U} /(\mathrm{g} \bullet \mathrm{min}))\end{array}$ \\
\hline contrast & $14.45 \pm 0.13 \mathrm{a}$ & $6.18 \pm 0.15 \mathrm{c}$ & $\begin{array}{l}328.22 \pm 14.36 \\
\mathrm{c}\end{array}$ & $\begin{array}{l}1091.82 \pm 18.04 \\
\mathrm{~b}\end{array}$ \\
$\mathrm{DA}-610 \mathrm{mg} / \mathrm{L}$ & $13.25 \pm 0.39 \mathrm{~b}$ & $7.45 \pm 0.25 \mathrm{~b}$ & $335.66 \pm 4.35 \mathrm{c}$ & $\begin{array}{l}1089.10 \pm 34.14 \\
\mathrm{~b}\end{array}$ \\
& & & $407.02 \pm 12.57$ & $\begin{array}{l}1108.59 \pm 36.73 \\
\mathrm{~b}\end{array}$ \\
$\mathrm{DA}-620 \mathrm{mg} / \mathrm{L}$ & $11.77 \pm 0.45 \mathrm{c}$ & $7.19 \pm 0.25 \mathrm{~b}$ & $\mathrm{a}$ & $\begin{array}{l}\mathrm{a} \\
\mathrm{CSN} 10 \mathrm{mg} / \mathrm{L}\end{array}$ \\
\hline
\end{tabular}




\begin{tabular}{lllll}
\hline CSN $20 \mathrm{mg} / \mathrm{L}$ & $13.22 \pm 0.42 \mathrm{~b}$ & $7.62 \pm 0.25 \mathrm{~b}$ & $371.71 \pm 4.39 \mathrm{~b}$ & $\begin{array}{l}1465.57 \pm 37.03 \\
\mathrm{a}\end{array}$ \\
& $12.42 \pm 0.29$ & $8.92 \pm 0.26 \mathrm{a}$ & $\begin{array}{l}380.35 \pm 7.19 \\
\mathrm{ab}\end{array}$ & $\begin{array}{l}1481.97 \pm 36.26 \\
\text { a-NSS110 mg/L }\end{array}$ \\
& $\mathrm{bc}$ & $8.72 \pm 0.19$ & $\begin{array}{l}379.20 \pm 14.65 \\
\mathrm{ab}\end{array}$ & $\begin{array}{l}1185.97 \pm 41.43 \\
\mathrm{~b}\end{array}$ \\
\hline
\end{tabular}

\section{Discussion and Conclusion}

Banana transplanting seedlings cultivate affected by various factors, which is beneficial to the growth, improve nutrient absorption, and increase the physiological resistance measures should be adopted. Rapid growth promoters can promote a variety of crop growth, increase its resistance. In this experiment, spraying a certain concentration of growth promoters can improve banana transplanting seedlings the plant, adjust the banana transplanting seedlings agronomic traits, nutrient absorption and physiological resistance, and different growth promoter regulation effect. Compared to fresh spraying on the leaf amine ester $20 \mathrm{mg} / \mathrm{L}$ could significantly promote the provisonal planting went high false stem, the growth of new foliage area and down three foliage area, increase dry matter accumulation, effectively reduce the leaf MDA content, proline content increased to promote and increase SOD activity. Spraying alpha naphthyl acetic acid sodium 10 $\mathrm{mg} / \mathrm{L}$ most conducive to promoting the banana transplanting seedlings NPK nutrients absorption, and in the lower leaf MDA content, proline content increased, the activity of SOD and POD, and hong-ju zhang similar results in chili [20]. Spray ShiFu phenol sodium nitrate effects on growth and physiological resistance of banana went to different, only in individual aspects, fresh as amine ester and alpha naphthyl acetic acid sodium. Combining this study shows that the banana transplanting seedlings cultivating process, fresh spraying on the leaf amine ester $20 \mathrm{mg} / \mathrm{L}$ raise false stem height, promote its shape formation, improve the false seeding high resistance; Spraying alpha naphthyl acetic acid sodium $10 \mathrm{mg} / \mathrm{L}$ promote NPK nutrient uptake and POD activity. So in banana transplanting seedlings breeding process, in order to get a robust provisonal planting banana went, should consider to mix or interval spraying amine ester, alpha naphthyl acetic acid sodium, as for the specific spraying effect still need further study.

\section{Acknowledgements}

Fund project: the banana industry technology system in danzhou comprehensive experimental station (CARS32-16); The ministry of agriculture species resources protection project (tropical crops) (16 rzzy - 01); Special activation fee of non-profit scientific research institution reform project (pzsfyl - 201709).

\section{Reference}

[1] Li Yuping flocity. China the banana industry present situation and the development countermeasures study [J]. China agriculture bulletin, 2008, 24 (8): 4473-4478.

Good.

[2] xiao-lin fan, liang xiao-qiang wang, etc. The banana nutrition and application [M]. Beijing: China agriculture press, 2007:175-182.

[3] dai-dong wu, WeiHuaFang chao-sheng li, etc. Summer and the high temperature season cultivation banana seed false seeding practical supporting technology [J]. China southern fruit trees, 2008, 37 (6): 33-35.

[4] Long Yifei. Banana seeding rapid cultivation matrix and regulation research [D]. Guangdong, south China agricultural university, 2012.

[5] yamada $r$ beautiful, bass, WeiShaoLong, etc. 2011 spring banana chilling injury research in our country and the chilling injury recovery countermeasures $[\mathrm{J}]$. Journal of southern agriculture, 2012 lancet (1): 46-49. 
[6] mao-fu li, shao-peng li, kris, etc. Research progress of banana frost-resistant [J]. Journal of south China university of tropical agriculture, 2005, 11 (01) : 51-54.

[7] Cheng Shimin, xiao-lin fan. Transplanting stock age of banana harvest and the influence of yield and quality [J]. Journal of fruit trees, 2014, 31 (5) : 879-884.

[8] xin-ling zhang. Banana older false seeding cultivation regulation technology and its impact on banana flower bud differentiation [D]. Guangdong, south China agricultural university, 2014.

[9] Fan Yongbai. Banana went to high-yield cultivation technology [J]. Journal of guangdong agricultural sciences, 2001 (6) : 25-26.

[10]Kulkarnia Manoj G, Stirka Wendy A, et al., Plant growth regulators enhance gold uptake in Brassica juncea [J]. Int J Phytoremediation, 2013, 15 (2) : 117-126.

[11] zhao-ping hu, li wei, jian-qiu Chen, et al. Sodium nitrate of phenol, DA - 6 and alpha naphthyl acetic acid sodium effect on yield and quality of eggplant [J]. China agriculture bulletin, 2013, 29 (25) : 168-172.

[12] rui-hai li, xu soldier, Huang Qi for, etc. The foliar fertilizer effect on seedling growth characteristics of rape [J]. Journal of nanjing agricultural university, 2008, 31 (3) : 91-96.

[13]Huang Zheng tree. Three kinds of plant growth regulator on the research of the physiological effects of banana seedlings spp.and [D]. Guangxi nanning: guangxi university, 2009.

[14] mandour n.s. Chen Qingxiang ze-qing wang etc. After adjustment effect of sodium nitrate of phenol on tomato growth [J]. Journal of zhejiang agricultural science, 2010, (2): 258-259.

[15] in the color lotus, liu, YanGong, etc. After phenol sodium nitrate part and its effect on seed germination of soybean [J]. Journal of soybean science, 2010, 29 (3) : 440-443.

[16]hong-ju zhang, huai-yong zhao, YuJiHua, etc. The greenhouse pepper fruit growth and the endogenous hormone content in the response of the external applied alpha naphthalene sodium acetate [J]. Chinese desert, 2013, 33 (6) : 1750-1758.

[17]LuRuKun. Agricultural chemical analysis [M]. Beijing: China agricultural science and technology publishing house, 2000

Li hopson.

[18]plant physiological and biochemical experiment principle and technology [M]. Beijing: higher education press, 2000.

[19]yelia Fan Fei, wang, etc. DA - 6 yellow lantern chili pepper seedlings under high temperature stress impact [J]. Journal of tropical crops, 2014, 35 (9) : 1795-1801.

[20] Guo Yunna yan-su li, He Chao xing, etc. Under the suitable sowing sodium naphthalene acetic acid effect on tomato seedling growth and physiological characteristics [J]. Journal of applied ecology, 2015, 26 (10): 3053-3058. 